\title{
Geologia
}

\section{Metais Pesados e a Dinâmica Lacustre no Parque Ecológico do Tietê - Centro de Lazer Engenheiro Goulart - RMSP}

\author{
Cyntia Helena Ravena Pinheiro (chhrpin@usp.br) e Joel Barbujiani Sígolo, \\ Departamento de Geologia Sedimentar e Ambiental - Instituto de Geociências - USP \\ R. do Lago 562, CEP 05508-080, São Paulo, SP, BRA
}

Recebido em 28 de novembro de 2005; aceito em 22 de maio de 2006

Palavras-chave: metais pesados, sedimentos lacustres, fitoplâncton.

\section{RESUMO}

Sedimentos lacustres em suspensão, do Parque Ecológico do Tietê - Centro de Lazer Engenheiro Goulart - RMSP, foram amostrados, retidos por dispositivos filtrantes e observados em microscópio eletrônico de varredura (MEV). Foi detectada a presença de diferentes espécies de diatomáceas e cloroflagelados que, com o recurso da incidência de elétrons retroespalhados, exibiam certa luminosidade, indicando a presença de metais pesados em suas estruturas. Com o emprego do EDS (energy dispersive spectrum) foi possível realizar análises químicas qualitativas pontuais das diferentes partes dessas estruturas com a finalidade de verificar o grau de interação e absorção desses metais por esses microorganismos. Os espectros EDS exibiram metais pesados, principalmente $\mathrm{Zn}, \mathrm{Fe}, \mathrm{Mn}, \mathrm{Cr}, \mathrm{Ni}$ e $\mathrm{Cu}$ associados a $\mathrm{Si}, \mathrm{Al}, \mathrm{S}, \mathrm{O}, \mathrm{P}, \mathrm{Ca}$ nas estruturas das frústulas das diatomáceas e em espécies de cloroflagelados. A aplicação do sistema MEV-EDS demonstrou ser um recurso auxiliar de observação e análise química que amplia as possibilidades da execução de um pré-diagnóstico ambiental capaz de orientar estudos mais específicos, sem a utilização de grandes quantidades de amostras desses organismos, tão difíceis de obter.

Keywords: heavy metals, lacustrine sediments, phytoplankton.

\section{ABSTRACT}

Suspended lacustrine sediments from the Tietê Ecological Park - Engenheiro Goulart Leisure Center, in the São Paulo Metropolitan Region, were retained by Millex filter units and examined using a scanning electron microscope (SEM). Different phytoplankton species were observed and heavy metals were detected in their organisms or structures parts, using point analyzes obtained by energy dispersive spectrometry (EDS). The EDS spectra showed mainly zinc, iron, manganese, chromium, nickel and copper associated with silicon, aluminum, sulfur, oxygen, phosphorus and calcium in the diatom frustules and Chloroflagellate species. These results together with chemical analyzes of the lake sediments and water permitted to verify their interaction and the degree of heavy metals adsorption. The SEM-EDS method provides additional observations and represents an analytical resource that supports the initial environmental diagnostics, and orients more detailed or specific studies using smaller samples of organisms than the traditional analytical methods. 


\section{INTRODUÇÃO}

A sedimentação em meio lacustre é o resultado da dinâmica de fundo dos lagos, existindo relações bastante acentuadas entre os aspectos físicos, químicos e biológicos dos sedimentos e a poluição existente nesses ambientes. Os sedimentos e o material em suspensão são coletados e analisados por representarem os resultados dessa dinâmica lacustre. A troca de elementos entre os sedimentos e a coluna d'água é de especial interesse devido à sua importância com respeito ao destino de diversos elementos químicos em lagos.

A interface sedimento-água caracteriza-se pelo aumento marcante na concentração de partículas e um decréscimo na velocidade do transporte por difusão, comparada com a lâmina de água acima desta interface. Nesse compartimento, a interação das espécies químicas e biológicas na maioria das vezes é intensa. Partículas mais finas do sedimento, que possuem elevada capacidade adsortiva e também maior superfície de contato, interagem com diversos compostos metálicos liberados para a coluna d'água, tornando essa região um local particularmente importante como fonte ou sumidouro desses elementos.

Análises químicas de perfis ou testemunhos de sedimentos podem representar a chave para a interpretação dos eventos que ocorreram num lago ao longo do tempo. Os elementos maiores ( $\mathrm{Si}, \mathrm{Al}, \mathrm{K}, \mathrm{Na}$ ) respondem pelo maior grupo na matriz dos sedimentos, seguidos pelos elementos químicos na forma de carbonatos ( $\mathrm{Ca}, \mathrm{Mg}$ ). Os nutrientes, como carbono orgânico, nitrogênio (N) e fósforo (P), contribuem com cerca de $10 \%$ dos sedimentos lacustres recentes. Elementos como manganês $(\mathrm{Mn})$, ferro $(\mathrm{Fe})$ e enxofre (S), estão presentes com cerca de $5 \%$ do peso total. Os elementos traço contribuem com cerca de $0,1 \%$. A maior parte dos metais traço é encontrada associada aos sedimentos de fundo e oferece uma chave excelente para avaliar o grau de poluição de um ambiente lacustre. Da mesma forma, a distribuição horizontal dos sedimentos pode ser usada para avaliar o padrão de transporte e sedimentação desses metais a partir de uma fonte poluente.

É necessário enfatizar que o estudo dos sedimentos também inclui espécies biológicas, como organismos microscópicos, que não podem ser convencionalmente separados dos componentes inorgânicos ou da matéria orgânica morta nos sedimentos. Esses microorganismos podem interferir na dinâmica do comportamento químico, implicando na dispersão e acumulação de muitos poluentes nos sedimentos. Geralmente, é difícil estabelecer relações claras entre os efeitos tóxicos agudos ou crônicos sobre a biota e a ocorrência de poluentes específicos nos sedimentos.

Frústulas de diatomáceas depositadas nesses sedimentos superficiais se preservam e constituem verdadeiros registros das condições ambientais lacustres. Podem ser utilizadas para relacionar esses organismos a variáveis químicas como $\mathrm{pH}$, concentração de nutrientes e contaminantes como metais pesados, podendo, com alguma restrição serem considerados biomonitores ambientais, (Håkansson et al., 1998; Medley e Clements, 1998).

A deposição desses organismos é um processo complexo que pode resultar na presença bastante variável do conjunto de espécies, de lugar para lugar, na superfície de fundo do lago, principalmente decorrente dos sucessivos eventos de ressuspensão e deposição.

É difícil obter organismos microscópicos presentes nos sedimentos em quantidade suficiente para efetuar análises químicas por técnicas convencionais, limitando os estudos de avaliação da interação desses com as espécies químicas contaminantes do meio. A utilização do EDS (energy dispersive spectrum) acoplado a microscópio eletrônico de varredura (MEV) permite a realização de análises químicas qualitativas pontuais que servem para o diagnóstico ambiental e podem orientar estudos de impacto mais detalhados.

\section{ÁREA DE ESTUDO}

A presente investigação foi realizada no lago principal do Parque Ecológico do Tietê - Centro de Lazer Engenheiro Goulart (PET) localizado na zona leste da cidade de São Paulo, à margem esquerda da Rodovia Ayrton Senna, sentido Aeroporto de Guarulhos (Figura 1).

Esse Parque foi criado pelo decreto $\mathrm{n}^{\circ} 7868$ de 30 de abril de 1976 como parte do Plano Hidrace do Departamento de Água e Energia Elétrica visando integrar os mecanismos de controle das cheias do rio Tietê na cidade de São Paulo ao uso recreativo da área e seus corpos d'água aí existentes. Os lagos preexistentes à instalação do PET surgiram das cavas resultantes da exploração de argilas (PROMON, 1976). Esses lagos recebem a carga doméstica e industrial de poluentes por diversos processos e do rio Tietê através de um canal, que liga o complexo de lagos ao leito do rio, bem como pelo transbordo deste no período das cheias.

Na década de 70, funcionou, na área do atual PET, o Aterro Sanitário Engenheiro Goulart. As lagoas de tratamento de chorume estão atualmente aterradas e situamse sob o leito retificado do rio Tietê e porção em área denominada como "bota-fora", compreendendo atualmente parte integrante da área de lazer do parque. Inúmeros trabalhos foram realizados no PET pelo IPT, CETESB e Universidade de São Paulo (Faculdade de Saúde Pública, Instituto de Geociências). Alguns deles, de caráter limnológico, procuraram identificar espécies fitoplanctônicas, zooplanctônicas e suas interações com o meio. 


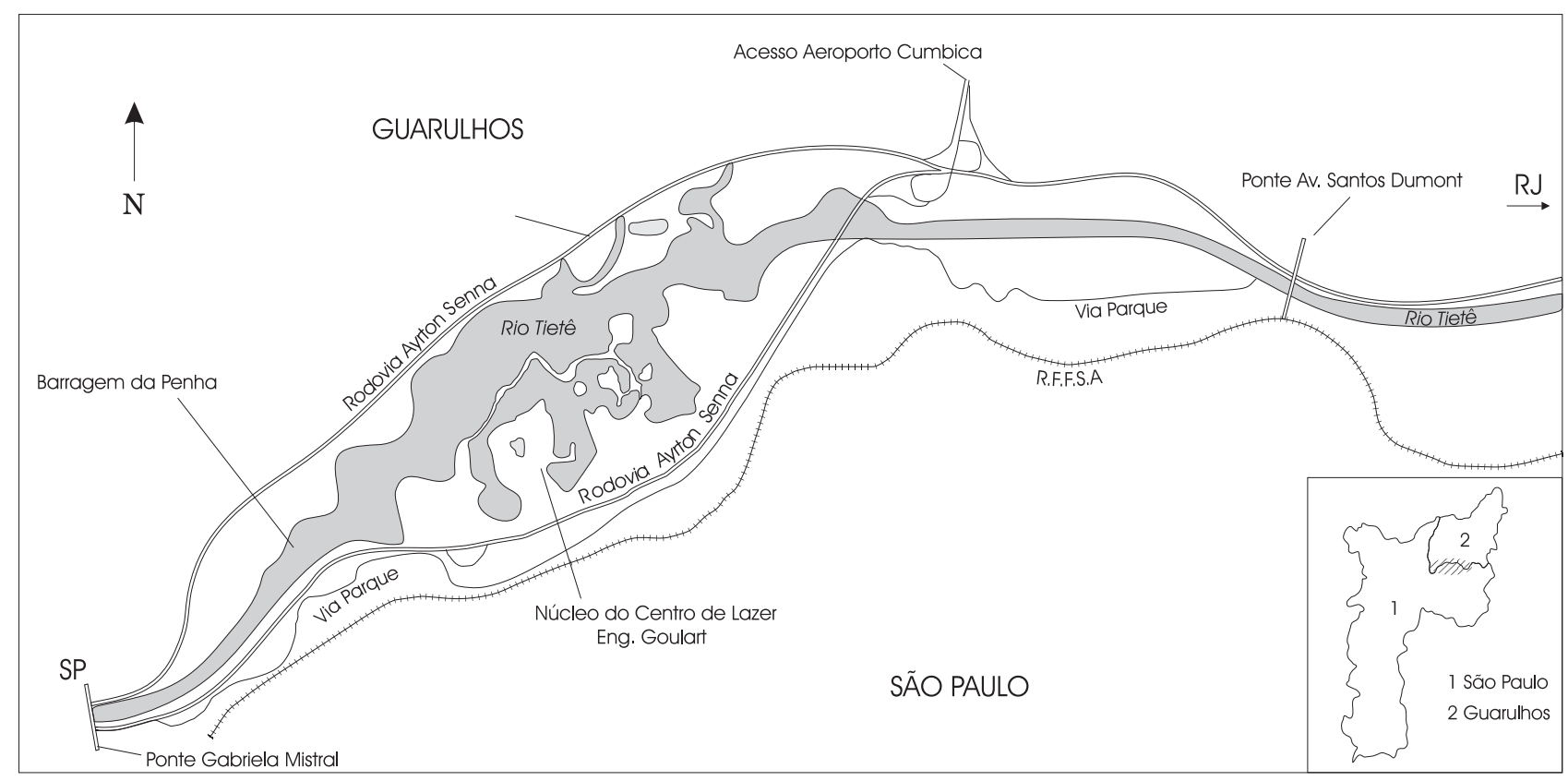

Figura 1. Localização do PET (modificado de DAEE).

Deker (2000) e Beyruth (1993) identificaram algumas espécies de diatomáceas, além de cloroflagelados, do gênero Trachelomonas, abundantes em habitat rico em matéria orgânica, em águas com baixos teores de oxigênio dissolvido e altas concentrações de sais de ferro e manganês em solução. Milani (2000), verificou que a condutividade elétrica da água (CE) obtida no fundo foi superior à obtida na superfície da coluna d'água, no verão. Apesar das pequenas quantidades de metais presentes na coluna d'água, os organismos zooplantônicos incorporaram seletivamente nutrientes como cobre, zinco, cádmio e chumbo, concentrando grandes quantidades de metais, principalmente no verão.

\section{MATERIAIS E MÉTODOS}

O procedimento de coleta dos sedimentos lacustres utilizado foi extraído de Mudroch e Azcue (1995), Hakanson e Jansson (1983) e Baudo, Giesy e Muntau (1990).

As amostras de sedimentos foram coletadas nas estações assinaladas no mapa georreferenciado da Figura 2. Na água da interface dos sedimentos de fundo com a coluna d'água foram determinados parâmetros físico-químicos a partir da leitura efetuada com o analisador Acquacheck. Tal equipamento possui eletrodos específicos para $\mathrm{pH}$, condutividade elétrica (CE em $\mu \mathrm{S} / \mathrm{cm}$ ) e oxigênio dissolvido (OD), além de sensor para a determinação da temperatura $\left(\mathrm{T}^{\circ} \mathrm{C}\right)$. $\mathrm{O}$ cabo conectado ao analisador permitiu que as leituras fossem efetuadas na profundidade da interface, sem que ocorresse perturbação dos sedimentos.

As amostras de sedimentos de fundo foram obtidas com amostrador piston-core tipo Kajak, modificado pelo acoplamento de hastes de trado. A água da interface, obtida em contato com os sedimentos no coletor, foi recolhida em um copo becker. Os particulados em suspensão presentes na água foram separados utilizando filtros Millex, da marca Millipore, de porosidade 0,8, 0,45 e 0,22 $\mu \mathrm{m}$, acoplados a uma seringa de $60 \mathrm{~mL}$. A porosidade menor assegurou a eliminação de partículas coloidais, além de bactérias que poderiam decompor algumas espécies químicas como $\mathrm{NO}_{3}^{-}$e $\mathrm{NO}_{2}^{-}$(Forti, 1998). As amostras de água que foram encaminhadas para a análise de cátions, incluindo metais pesados, foram acidificadas em $\mathrm{pH}<2$ com $\mathrm{HNO}_{3}$ e armazenadas em frascos de polietileno. Para os ânions, não houve preservação química das amostras, permanecendo sob refrigeração a temperatura próxima de $4^{\circ} \mathrm{C}$. As técnicas analíticas empregadas foram, para a determinação dos metais, a espectrofotometria de absorção atômica (AAS) e a cromatografia líquida para os ânions, ambas realizadas pelo Centro de Pesquisas de Águas Subterrâneas (CEPAS) do Departamento de Geologia Sedimentar e Ambiental (GSA) do IGc/USP.

Os dispositivos filtrantes de $0,8 \mu \mathrm{m}$ contendo os particulados existentes na água da interface foram secos a $40^{\circ} \mathrm{C}$ e cuidadosamente abertos de maneira a se retirar o elemento filtrante de seu interior. Esses filtros foram 


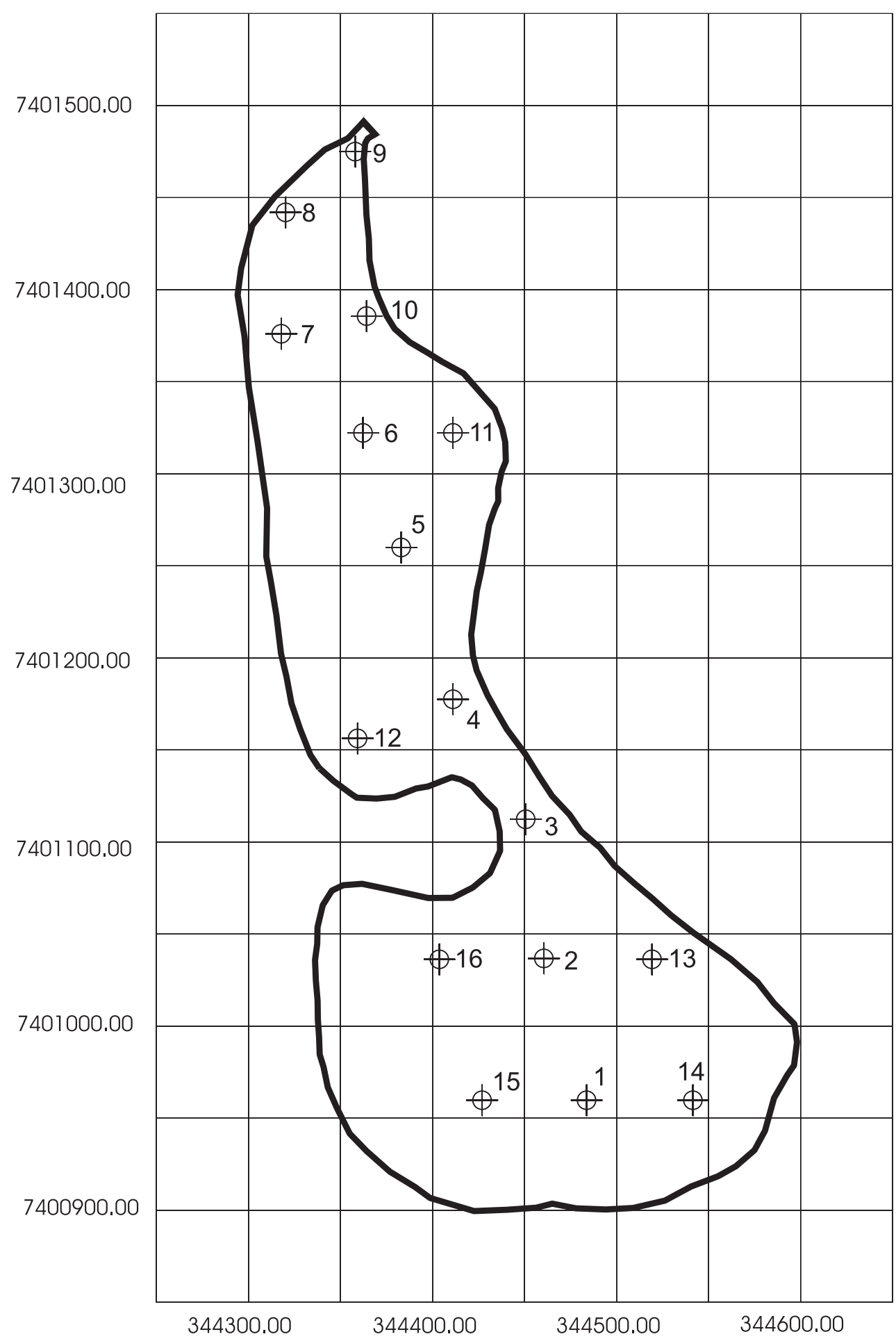

Figura 2. Mapa georreferenciado do lago principal do PET e as estações de amostragem. 
examinados ao MEV submetido ao baixo vácuo (marca JSM, modelo 560LV) do Laboratório de Microscopia Eletrônica de Varredura do Núcleo de Pesquisa em Geoquímica e Geofísica da Litosfera (NUPEGEL/USP). Nessa condição de pressão (26 Ka) tornou-se desnecessário o recobrimento das amostras.

\section{RESULTADOS}

As concentrações de cátions (metais) e ânions obtidas para as amostras da água da interface bem como os valores de $\mathrm{pH}, \mathrm{CE}, \mathrm{T}\left({ }^{\circ} \mathrm{C}\right)$ e OD da água da interface são exibidos na Tabela 1.

Tanto o cobre quanto o níquel e o cromo não foram encontrados dentro dos limites de detecção da técnica analítica utilizada (absorção atômica). Quanto ao zinco, as concentrações encontravam-se bem acima do limite de 0,008 mg/L. O maior valor foi observado nas estações PET 5 e $6(0,11 \mathrm{mg} / \mathrm{L})$ e os menores nas PET 3, 10 e 15 (0,02 mg/L). As concentrações mais elevadas de íons de ferro presentes na água da interface ocorreram nas estações PET 1 e 10 (0,47 e 0,39 mg/L). As demais estações também exibiram concentrações do metal variando entre 0,07 mg/L (PET 3 e 12) e $0,27 \mathrm{mg} / \mathrm{L}$ (PET 5). Os íons $\mathrm{Mn}^{2+}$ estiveram presentes com maiores concentrações nas estações PET 3 e 9, variando entre 0,12 e 0,13 mg/L. Nas estações PET 1, 14, 5, 6 entre 0,07 e $0,10 \mathrm{mg} / \mathrm{L}$. Os menores valores foram encontrados nas estações PET 2, 4, 8, 11, 12, 13 e 15, 0,02 mg/L e 0,03 mg/L, igual ou pouco acima do limite de detecção do equipamento (0,02 mg/L). A condutividade elétrica encontrada para a estação PET 1 foi mais elevada ( $212 \mu \mathrm{S} / \mathrm{cm})$, que das estações
2, 3, 4, 5, 6, 7, 8 e 9 com média de $180 \mu \mathrm{S} / \mathrm{cm}$. As PET 10, 11, 12, 13, 14, 15 e 16 exibiram valores mais baixos (média de $75 \mu \mathrm{m})$. O valor médio de $\mathrm{pH}$ da água da interface foi 7,96, sendo superior ao dos sedimentos de topo $(6,85)$. As estações PET 10, 11, 12, 13, 14, 15 e 16 apresentaram valores de $\mathrm{pH}$ mais elevados, variando entre 8,5 e 9,0.

Com exceção do níquel, as concentrações dos metais pesados nos sedimentos de topo $(0$ - $3 \mathrm{~cm})$ foram superiores aos sedimentos de base (37 - $40 \mathrm{~cm}$ ), amostras $1 \mathrm{~F}$ a $16 \mathrm{~F}$, como podem ser verificadas na Tabela 2. As menores concentrações de metais pesados nas estações 3, 4 e 9 estão relacionadas à diferença textural das amostras desses sedimentos, areno-argilosos (PET 4 e 9) e areno-siltoargilosos (PET 3), diferentes dos sedimentos das demais estações que são argilo-siltosos (PET 1 e 7) e os demais silto-argilosos.

Os fatores de correlação dos metais entre si e com os percentuais de matéria orgânica, umidade dos sedimentos e perda ao fogo encontram-se na Tabela 3.

As melhores correlações foram obtidas entre $\mathrm{Cu}, \mathrm{Cr}$, $\mathrm{Al}_{2} \mathrm{O}_{3}$ e $\mathrm{Zn}$, entre $\mathrm{Zn}$ e $\% \mathrm{P}_{2} \mathrm{O}_{5}$, $\mathrm{Zn}$ e \% perda ao fogo e $\% \mathrm{P}_{2} \mathrm{O}_{5}$ e \% de perda ao fogo. Entre $\% \mathrm{Fe}_{2} \mathrm{O}_{3}$ e os metais $\mathrm{Zn}$, $\mathrm{Cr}$ e $\mathrm{Al}_{2} \mathrm{O}_{3}$, entre $\mathrm{Cr}$ e $\% \mathrm{P}_{2} \mathrm{O}_{5}$. Isso explica a presença de metais como $\mathrm{Zn}$, Fe e $\mathrm{Cu}$ associados a fósforo e alumínio nos espectros EDS, acoplado ao MEV, obtidos para as análises químicas qualitativas pontuais de organismos presentes nesse ambiente lacustre.

Diversas espécies de diatomáceas foram observadas, com o auxílio do MEV, nos particulados em suspensão, retidos nos filtros Millex. A diversidade desses organismos pode ser verificada nas imagens da Figura 3.

Tabela 1. Parâmetros físico-químicos e químicos da água da interface (L.D. = limite de detecção; n.d. = não determinado).

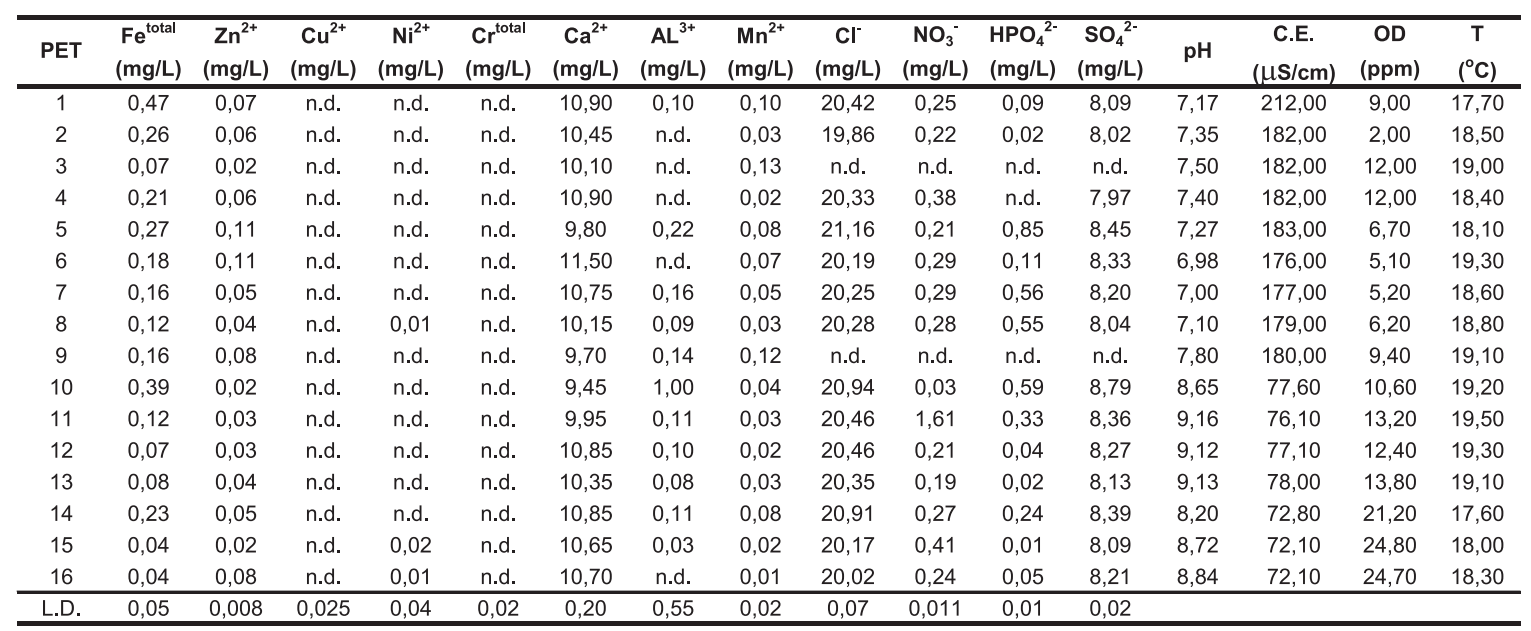


Tabela 2. Tabela de parâmetros físico-químicos e químicos para os sedimentos de topo $(0-3 \mathrm{~cm})$, PET 1 a 16 e base $(37-40 \mathrm{~cm})$, PET 1F a 16F (L.D. = limite de detecção, L.Q. = limite de quantificação).

\begin{tabular}{|c|c|c|c|c|c|c|c|c|c|c|c|c|c|c|c|c|c|c|c|}
\hline PET & $\begin{array}{l}\text { Latitude } \\
\text { (m) }\end{array}$ & $\begin{array}{l}\text { Longitude } \\
\text { (m) }\end{array}$ & $\begin{array}{l}\text { Prof } \\
\text { (m) }\end{array}$ & $\begin{array}{c}\mathrm{Fe}_{2} \mathrm{O}_{3} \\
\%\end{array}$ & $\begin{array}{c}\mathrm{Zn} \\
(\mathrm{ppm})\end{array}$ & $\begin{array}{c}\mathrm{Cu} \\
(\mathrm{ppm})\end{array}$ & $\begin{array}{c}\mathrm{Ni} \\
(\mathrm{ppm})\end{array}$ & $\begin{array}{c}\mathrm{Cr} \\
(\mathrm{ppm})\end{array}$ & $\begin{array}{c}\mathrm{P}_{2} \mathrm{O}_{5} \\
(\%)\end{array}$ & $\begin{array}{l}\mathrm{CaO} \\
(\%)\end{array}$ & $\begin{array}{c}\mathrm{Al}_{2} \mathrm{O}_{3} \\
(\%)\end{array}$ & $\begin{array}{l}\mathrm{SiO}_{2} \\
(\%)\end{array}$ & $\begin{array}{c}\mathrm{MnO} \\
(\%)\end{array}$ & $\begin{array}{l}\text { MO } \\
(\%)\end{array}$ & $\begin{array}{c}\text { Umid } \\
(\%)\end{array}$ & $\begin{array}{l}\text { Arg } \\
\text { (\%) }\end{array}$ & pH & $\begin{array}{c}\text { Eh } \\
(\mathrm{mV})\end{array}$ & $\begin{array}{l}\text { P.F. } \\
\text { (\%) }\end{array}$ \\
\hline 1 & 7400960 & 344484 & 2,90 & 5,97 & 295 & 69 & 15 & 78 & 0,19 & 0,30 & 29,29 & 41,56 & 0,04 & 12,9 & 69,11 & 51 & 6,80 & -333 & 18,69 \\
\hline 2 & 7401036 & 344462 & 2,60 & 5,51 & 293 & 71 & 15 & 76 & 0,19 & 0,36 & 27,59 & 43,81 & 0,04 & 9,1 & 57,24 & 39 & 6,97 & -327 & 18,41 \\
\hline 3 & 7401113 & 344451 & 1,20 & 3,25 & 210 & 55 & 15 & 46 & 0,15 & 0,33 & 17,44 & 60,85 & 0,04 & 11,7 & 59,92 & 22 & 6,41 & -283 & 14,13 \\
\hline 4 & 7401178 & 344411 & 2,10 & 2,83 & 137 & 27 & 15 & 51 & 0,14 & 0,23 & 20,00 & 61,09 & 0,03 & 5,0 & 42,70 & 27 & 7,01 & -314 & 12,27 \\
\hline 5 & 7401260 & 344384 & 2,60 & 5,94 & 325 & 75 & 36 & 92 & 0,19 & 0,35 & 28,98 & 42,30 & 0,04 & 8,3 & 76,11 & 45 & 6,83 & -317 & 19,65 \\
\hline 6 & 7401322 & 344362 & 2,70 & 6,05 & 316 & 73 & 26 & 81 & 0,19 & 0,32 & 29,53 & 41,41 & 0,04 & 8,5 & 60,75 & 40 & 6,35 & -311 & 18,99 \\
\hline 7 & 7401376 & 344320 & 2,70 & 5,86 & 335 & 83 & 28 & 79 & 0,18 & 0,29 & 29,39 & 43,18 & 0,04 & 8,8 & 70,91 & 65 & 6,97 & -297 & 18,12 \\
\hline 8 & 7401442 & 344320 & 2,10 & 5,76 & 390 & 107 & 26 & 76 & 0,18 & 0,36 & 27,87 & 45,22 & 0,04 & 7,4 & 72,45 & - & 6,93 & -317 & 17,44 \\
\hline 9 & 7401475 & 344358 & 1,30 & 4,07 & 133 & 30 & 15 & 32 & 0,09 & 0,18 & 14,27 & 68,81 & 0,04 & 1,5 & 33,34 & 21 & 6,89 & -308 & 5,53 \\
\hline 10 & 7401386 & 344367 & 2,48 & 6,41 & 325 & 83 & 41 & 84 & 0,19 & 0,35 & 28,29 & 42,86 & 0,05 & 5,6 & 73,57 & 30 & 6,83 & -326 & 18,67 \\
\hline 11 & 7401322 & 344411 & 2,48 & 5,57 & 318 & 73 & 35 & 85 & 0,19 & 0,37 & 28,90 & 42,32 & 0,04 & 6,2 & 62,71 & 31 & 6,28 & -321 & 19,01 \\
\hline 12 & 7401156 & 344360 & 2,38 & 5,64 & 314 & 75 & 28 & 76 & 0,19 & 0,35 & 28,48 & 42,73 & 0,04 & 5,9 & 70,09 & 40 & 7,06 & -318 & 19,08 \\
\hline 13 & 7401036 & 344520 & 2,40 & 5,94 & 286 & 72 & 38 & 80 & 0,20 & 0,43 & 27,68 & 41,88 & 0,04 & 6,2 & 79,77 & 36 & 7,06 & -310 & 20,78 \\
\hline 14 & 7400960 & 344542 & 2,52 & 5,89 & 318 & 75 & 28 & 84 & 0,19 & 0,50 & 28,93 & 42,63 & 0,04 & 6,4 & 63,19 & 41 & 6,50 & -322 & 18,98 \\
\hline 15 & 7400960 & 344426 & 2,82 & 5,86 & 290 & 72 & 31 & 79 & 0,18 & 0,53 & 26,16 & 45,22 & 0,04 & 5,7 & 72,34 & 28 & 6,97 & -362 & 17,85 \\
\hline 16 & 7401036 & 344404 & 2,21 & 4,72 & 243 & 55 & 23 & 76 & 0,16 & 0,51 & 28,08 & 45,91 & 0,03 & 6,6 & 61,40 & 41 & 7,02 & -333 & 17,95 \\
\hline $1 \mathrm{~F}$ & 7400960 & 344484 & 2,90 & 4,57 & 268 & 43 & 42 & 76 & 0,16 & 0,23 & 28,11 & 45,03 & 0,02 & 6,4 & 49,00 & 57 & 6,53 & -285 & 17,67 \\
\hline $2 \mathrm{~F}$ & 7401036 & 344462 & 2,60 & 4,28 & 168 & 25 & 35 & 58 & 0,14 & 0,12 & 28,07 & 49,52 & 0,01 & 3,0 & 40,00 & 54 & 6,64 & -246 & 13,63 \\
\hline $4 \mathrm{~F}$ & 7401178 & 344411 & 2,10 & 1,66 & 62 & 15 & 24 & 21 & 0,07 & 0,09 & 15,18 & 69,14 & 0,01 & 4,4 & 39,00 & 21 & 6,14 & -229 & 9,17 \\
\hline $5 \mathrm{~F}$ & 7401260 & 344384 & 2,60 & 4,50 & 318 & 52 & 38 & 69 & 0,17 & 0,23 & 27,43 & 45,34 & 0,02 & 11,2 & 54,00 & 67 & 6,27 & -292 & 17,84 \\
\hline $6 \mathrm{~F}$ & 7401322 & 344362 & 2,70 & 4,73 & 232 & 42 & 41 & 70 & 0,17 & 0,26 & 31,33 & 41,98 & 0,02 & 6,3 & 59,00 & 70 & 6,15 & -294 & 17,94 \\
\hline $7 \mathrm{~F}$ & 7401376 & 344320 & 2,70 & 5,18 & 284 & 66 & 42 & 74 & 0,17 & 0,27 & 30,14 & 43,79 & 0,02 & 4,6 & 50,00 & 55 & 6,70 & -291 & 17,27 \\
\hline $8 \mathrm{~F}$ & 7401442 & 344320 & 2,10 & 4,04 & 181 & 34 & 34 & 50 & 0,10 & 0,15 & 21,02 & 59,80 & 0,02 & 2,9 & 39,00 & 42 & 6,73 & -277 & 10,67 \\
\hline $10 \mathrm{~F}$ & 7401386 & 344367 & 2,48 & 4,82 & 409 & 55 & 42 & 73 & 0,16 & 0,26 & 30,73 & 43,07 & 0,03 & 14,7 & 48,00 & 46 & 6,29 & -296 & 17,83 \\
\hline $11 \mathrm{~F}$ & 7401322 & 344411 & 2,48 & 4,91 & 381 & 61 & 37 & 64 & 0,18 & 0,20 & 26,91 & 47,77 & 0,03 & 7,9 & 60,00 & 43 & 6,45 & -262 & 16,27 \\
\hline $12 \mathrm{~F}$ & 7401156 & 344360 & 2,38 & 4,55 & 220 & 41 & 42 & 67 & 0,16 & 0,24 & 30,49 & 43,29 & 0,02 & 7,2 & 48,00 & 58 & 6,50 & -282 & 17,88 \\
\hline $14 \mathrm{~F}$ & 7400960 & 344542 & 2,52 & 4,71 & 279 & 42 & 34 & 73 & 0,15 & 0,25 & 26,29 & 47,22 & 0,03 & 6,1 & 56,00 & 69 & 6,29 & -306 & 16,96 \\
\hline $15 \mathrm{~F}$ & 7400960 & 344426 & 2,82 & 4,46 & 237 & 41 & 32 & 66 & 0,17 & 0,21 & 27,82 & 46,21 & 0,03 & 6,1 & 55,00 & 39 & 6,51 & -293 & 17,43 \\
\hline $16 \mathrm{~F}$ & 7401036 & 344404 & 2,21 & 4,41 & 206 & 36 & 31 & 69 & 0,15 & 0,16 & 26,90 & 46,93 & 0,03 & 7,5 & 52,00 & 79 & 6,20 & -261 & 16,87 \\
\hline L.D. & & & & 0,002 & 1 & 2 & 2 & 2 & 0,007 & 0,01 & 0,01 & 0,01 & 0,003 & & & & & & \\
\hline L.Q. & & & & 0,007 & 3 & 7 & 7 & 7 & 0,023 & 0,03 & 0,03 & 0,03 & 0,01 & & & & & & \\
\hline
\end{tabular}

Tabela 3. Fatores de correlação de Pearson para os parâmetros químicos e físico-químicos dos sedimentos de topo.

\begin{tabular}{|c|c|c|c|c|c|c|c|c|c|c|c|c|c|c|c|c|}
\hline & $\% \mathrm{Fe}_{2} \mathrm{O}_{3}$ & $\mathrm{Zn}$ & $\mathrm{Cu}$ & $\mathrm{Ni}$ & $\mathrm{Cr}$ & $\% \mathrm{P}_{2} \mathrm{O}_{5}$ & $\% \mathrm{CaO}$ & $\% \mathrm{Al}_{2} \mathrm{O}_{3}$ & $\%$ MO & \%umid & \%arg & $\% \mathrm{SiO}_{2}$ & $\% \mathrm{MnO}_{2}$ & prof & $\mathrm{pH}$ & \%P.F. \\
\hline$\% \mathrm{Fe}_{2} \mathrm{O}_{3}$ & 1 & 0,85078 & 0,79798 & 0,67075 & 0,84950 & 0,77811 & 0,41296 & 0,83900 & 0,14012 & 0,74082 & 0,52759 & $-0,87930$ & 0,59956 & 0,76528 & $-0,00510$ & 0,73916 \\
\hline $\mathrm{Zn}$ & & 1 & 0,97694 & 0,59535 & 0,84451 & 0,83614 & 0,38564 & 0,85117 & 0,35726 & 0,82324 & 0,60507 & $-0,87010$ & 0,49159 & 0,64229 & $-0,11160$ & 0,81437 \\
\hline $\mathrm{Cu}$ & & & 1 & 0,55744 & 0,75101 & 0,77041 & 0,39503 & 0,75262 & 0,33521 & 0,80702 & 0,53632 & $-0,78170$ & 0,53804 & 0,51858 & $-0,05780$ & 0,73708 \\
\hline $\mathrm{Ni}$ & & & & 1 & 0,69937 & 0,58840 & 0,43722 & 0,56875 & $-0,23780$ & 0,70572 & 0,13353 & $-0,60970$ & 0,48721 & 0,43372 & $-0,03470$ & 0,60317 \\
\hline $\mathrm{Cr}$ & & & & & 1 & 0,91805 & 0,57742 & 0,96415 & 0,27350 & 0,80578 & 0,58154 & $-0,96970$ & 0,28496 & 0,85209 & $-0,06020$ & 0,93330 \\
\hline$\% \mathrm{P}_{2} \mathrm{O}_{5}$ & & & & & & 1 & 0,52057 & 0,90564 & 0,45707 & 0,84451 & 0,51922 & $-0,95720$ & 0,34913 & 0,78831 & $-0,10210$ & 0,97705 \\
\hline$\% \mathrm{CaO}$ & & & & & & & 1 & 0,50456 & 0,04196 & 0,54494 & 0,06903 & $-0,55130$ & $-0,04740$ & 0,38589 & 0,01053 & 0,61499 \\
\hline$\% \mathrm{Al}_{2} \mathrm{O}_{3}$ & & & & & & & & 1 & 0,32758 & 0,75394 & 0,70017 & $-0,98470$ & 0,20905 & 0,87003 & $-0,00870$ & 0,92233 \\
\hline$\% \mathrm{MO}$ & & & & & & & & & 1 & 0,39575 & 0,47129 & $-0,35210$ & 0,07280 & 0,25698 & $-0,27540$ & 0,45107 \\
\hline \%umid & & & & & & & & & & 1 & 0,49144 & $-0,81370$ & 0,41623 & 0,58525 & 0,10405 & 0,86393 \\
\hline \%arg & & & & & & & & & & & 1 & $-0,84540$ & $-0,00760$ & 0,62375 & 0,19129 & $-0,95370$ \\
\hline$\% \mathrm{SiO}_{2}$ & & & & & & & & & & & & 1 & $-0,30400$ & $-0,85900$ & 0,03280 & 0,22856 \\
\hline$\% \mathrm{MnO}_{2}$ & & & & & & & & & & & & & 1 & 0,15939 & $-0,22430$ & 0,76502 \\
\hline prof & & & & & & & & & & & & & & 1 & 0,09158 & 0,76503 \\
\hline $\mathrm{pH}$ & & & & & & & & & & & & & & & 1 & $-0,06480$ \\
\hline$\%$ P.F. & & & & & & & & & & & & & & & & 1 \\
\hline
\end{tabular}




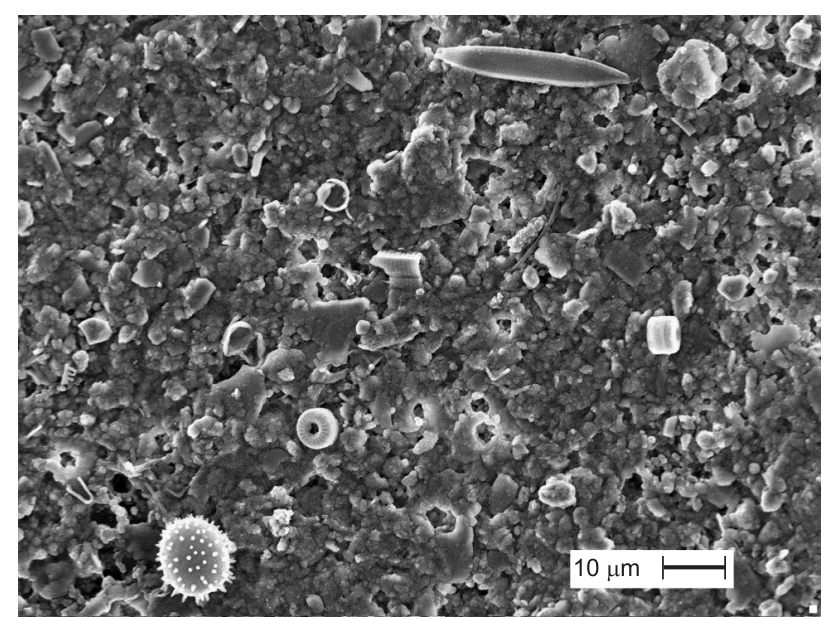

Figura 3. Imagem ao MEV de particulados em suspensão das estações de amostragem PET 8 exibindo diversas espécies fitoplanctônicas.

É possível através desta notar-se a grande variedade de algas diatomáceas com diferentes formas, bem como de um provável cloroflagelado na porção inferior à esquerda. Frústulas de diatomáceas podem ser observadas na porção central (estrutura circular perfurada) e nordeste da imagem (estrutura pinada ou fusiforme). Quando observada com o recurso de elétrons retrodifusos a imagem permite identificar a presença de metais pela maior luminosidade exibida. $\mathrm{Na}$ imagem em split da Figura 4a os pontos luminosos foram identificados e analisados com o EDS. As presenças de $\mathrm{Ca}$, $\mathrm{Fe}, \mathrm{Zn}, \mathrm{Mn}$ e Cu podem ser verificadas no espectro EDS do ponto 1, na Figura 4b. Os espectros dos demais pontos analisados exibem presença dos metais pesados $\mathrm{Cr}, \mathrm{Ni}$, Mo e $\mathrm{Mn}$, mas não puderam ser associados a estruturas biológicas identificáveis.

O ponto 1 refere-se provavelmente a alga do grupo dos cloroflagelados, do gênero Trachelomonas, identificado anteriormente no lago do PET por Deker (2000) e Beyruth (1993). Branco (1986) descreve esse gênero caracterizado por células solitárias encerradas em uma lorica rígida de forma elipsoidal, ovóide ou esférica, com superfície lisa ou apresentando rugosidades ou espinhos curtos. Os sais de ferro em solução podem ter impregnado suas células na forma de hidróxidos. Canter-Lund e Lund (1996) fazem referência a esse processo.

A Figura 5a contém imagem obtida com o MEV, em split, com evidente presença de metais pesados na estrutura esferoidal a noroeste e espectro EDS da análise pontual nela realizada. Essa estrutura pode ser de representante do gênero das Chlamydomonas, também identificado por Deker (2000) e Beyruth (1993) no lago do PET. Assim como as Trachelomonas, as Chlamydomonas pertencem ao grupo das algas cloroflageladas, sendo unicelulares, esféricas, elipsoidais ou piriformes, possuindo dois flagelos. Quando mortas, sem movimento, seus flagelos podem não ser visíveis e elas podem ser confundidas com Clorellas se não fossem maiores que estas. $\mathrm{O}$ tamanho (aproximadamente $10 \mu \mathrm{m}$ ) observado na imagem da Figura 5a coincide com o apresentado por Branco (1986) para as Chlamydomonas. O espectro obtido para a análise pontual qualitativa não exibiu a presença de metais além do Fe (Figura 5b). A estrutura cilíndrica a sudeste em formato de flauta, provavelmente frústula de alguma espécie de diatomácea, não apresentou sinais da presença de metais pesados.

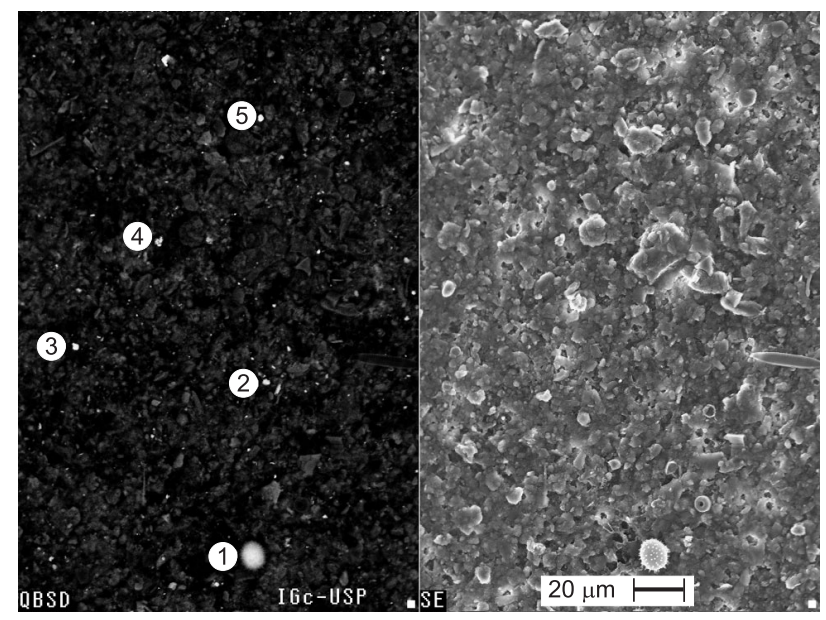

Figura 4a. Imagem MEV, com recurso de split, de particulados em suspensão da estação de amostragem PET 8. As estruturas assinaladas ( 1 a 5 ) foram analisadas com EDS acoplado ao MEV.

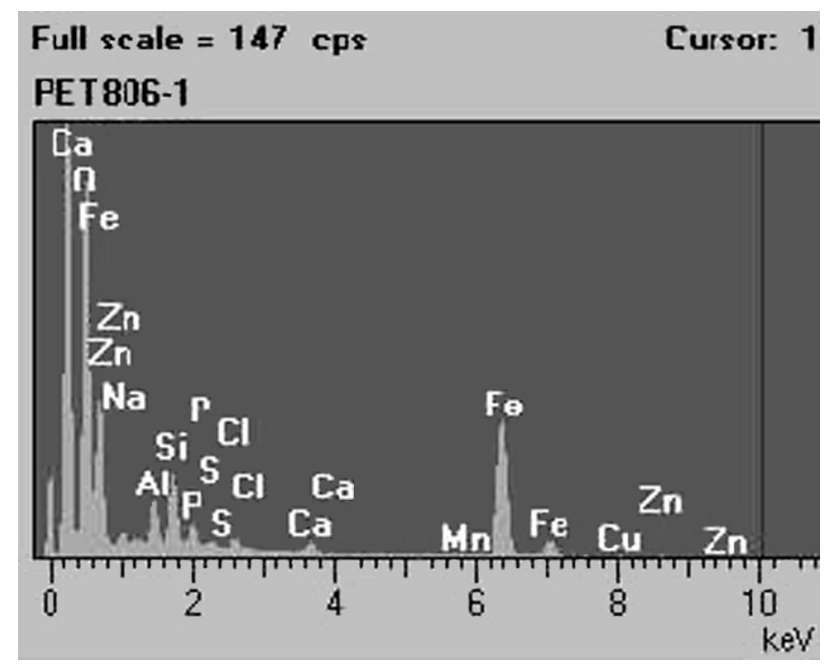

Figura 4b. Espectro EDS da estrutura 1. 
A estrutura presente na imagem do MEV da Figura 6a trata-se possivelmente de valvas que compõem a frústula de uma diatomácea cêntrica e que se dispõe de forma radial, ou a vista valvar de uma forma pinada cujas estrias, dispostas em duas séries ao longo do eixo longitudinal, são separadas por uma área mediana sem ornamentos. Verifica-se no espectro EDS obtido para a análise da camada mais externa (Figura 6b) a presença do Si, Al, C, O e Fe, acompanhados de Ti e K. A presença de Si e O deve-se à composição silicosa característica da frústula. Seguindo para o interior da estrutura, a análise química qualitativa pontual realizada para a primeira série de estrias exibiu a presença de metais $\mathrm{Cu}$ e $\mathrm{Zn}$ e de $\mathrm{S}$, além dos constituintes da camada mais externa (espectro EDS da Figura 6c). O resultado da análise da segunda série de estrias, central, foi semelhante ao da anterior (espectro EDS da Figura 6d).

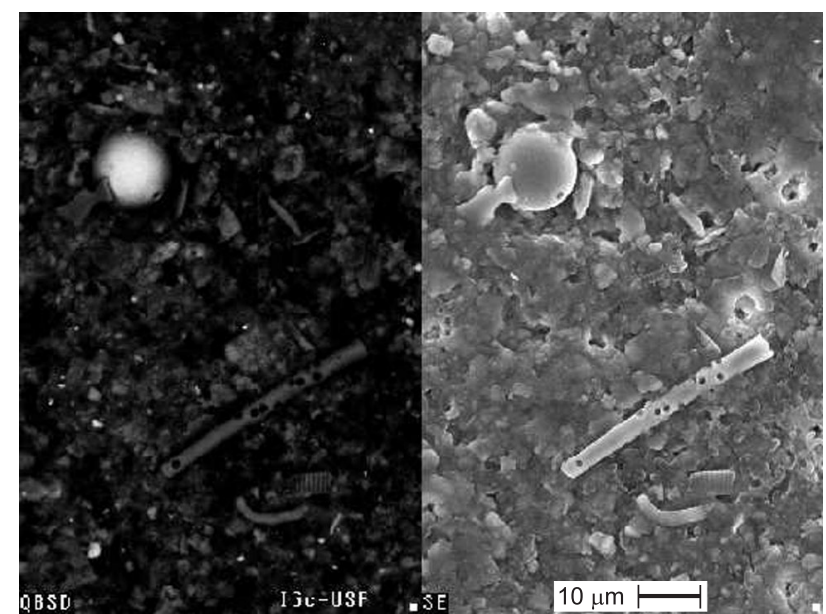

Figura 5a. Imagem obtida em MEV, em split de espécies fitoplanctônicas presentes na estação PET 8.

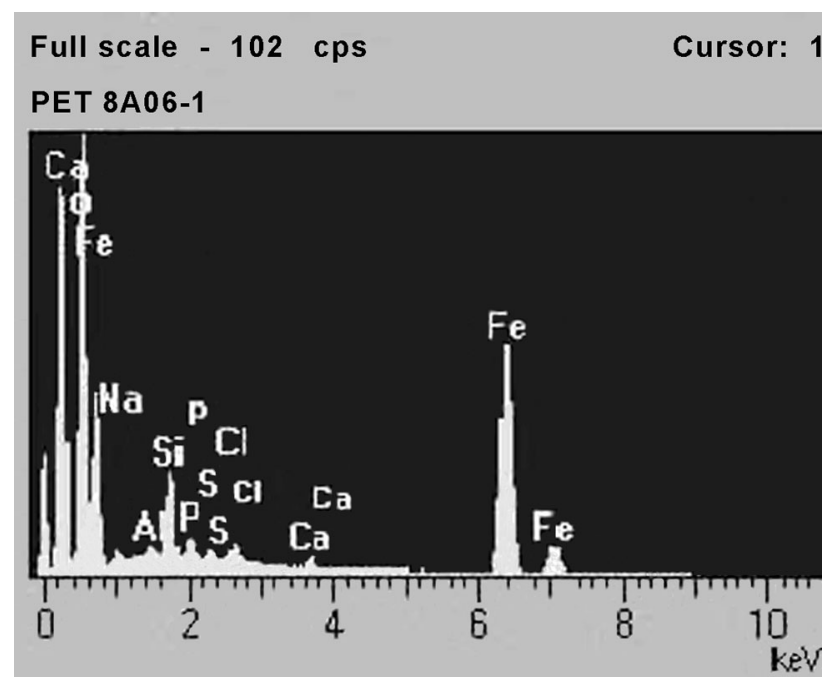

Figura 5b. Espectro EDS da estrutura esferoidal.

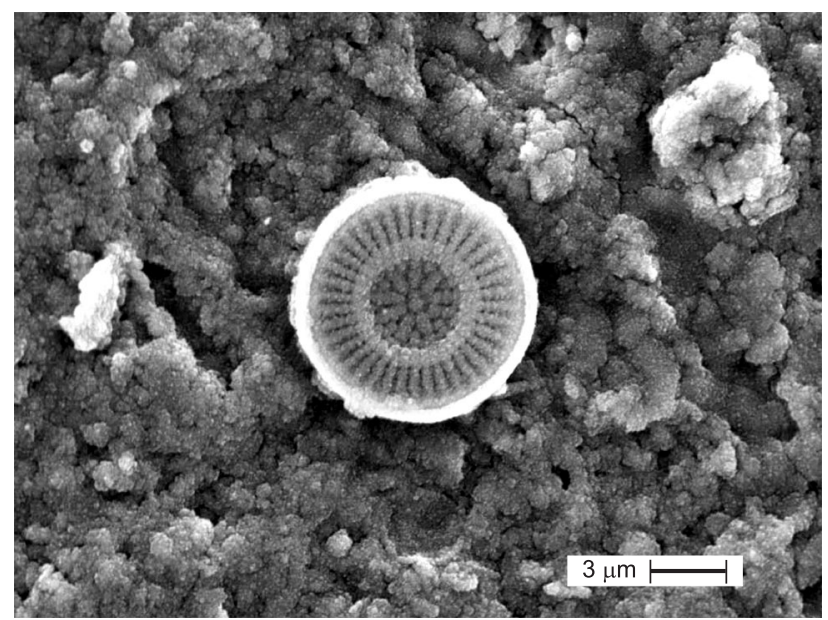

Figura 6a. Imagem de frústula diatomácea presente nas estações PET 9 e PET 14, obtidas em MEV. 


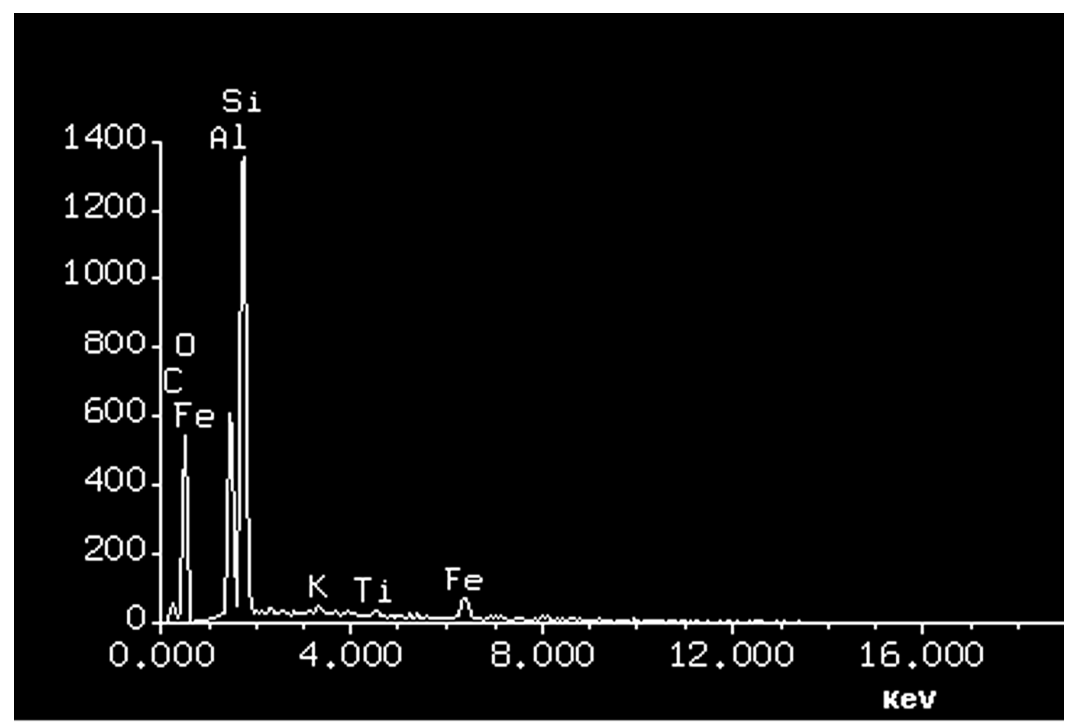

Figura 6b. Espectro EDS da camada mais externa da frústula.

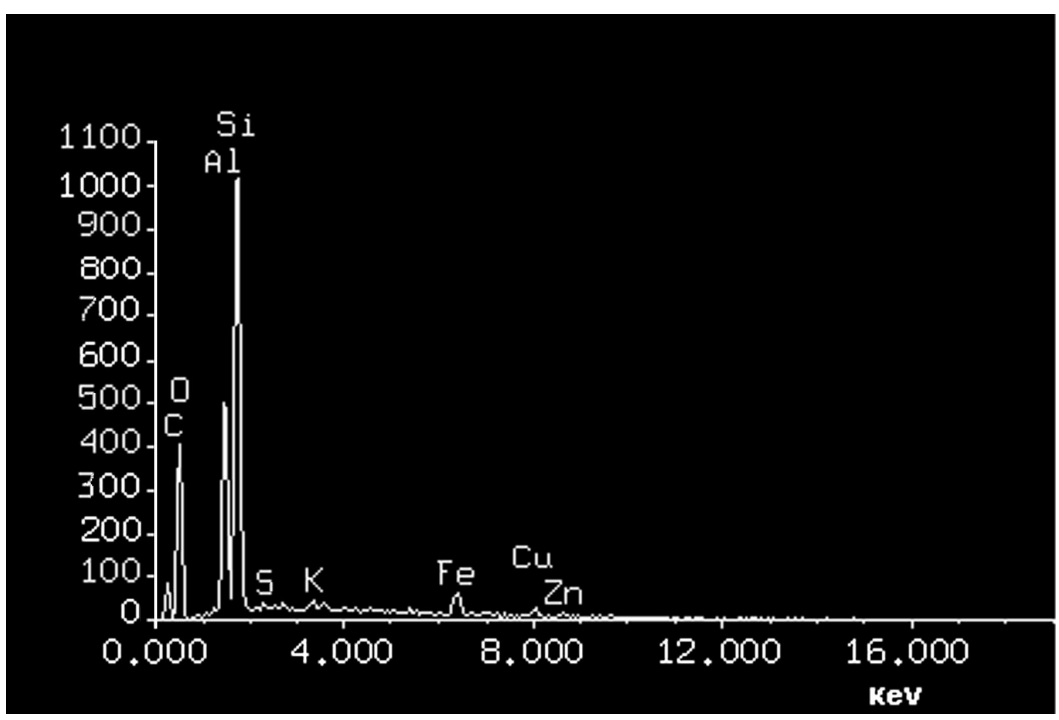

Figura 6c. Espectro EDS da camada interna intermediária.

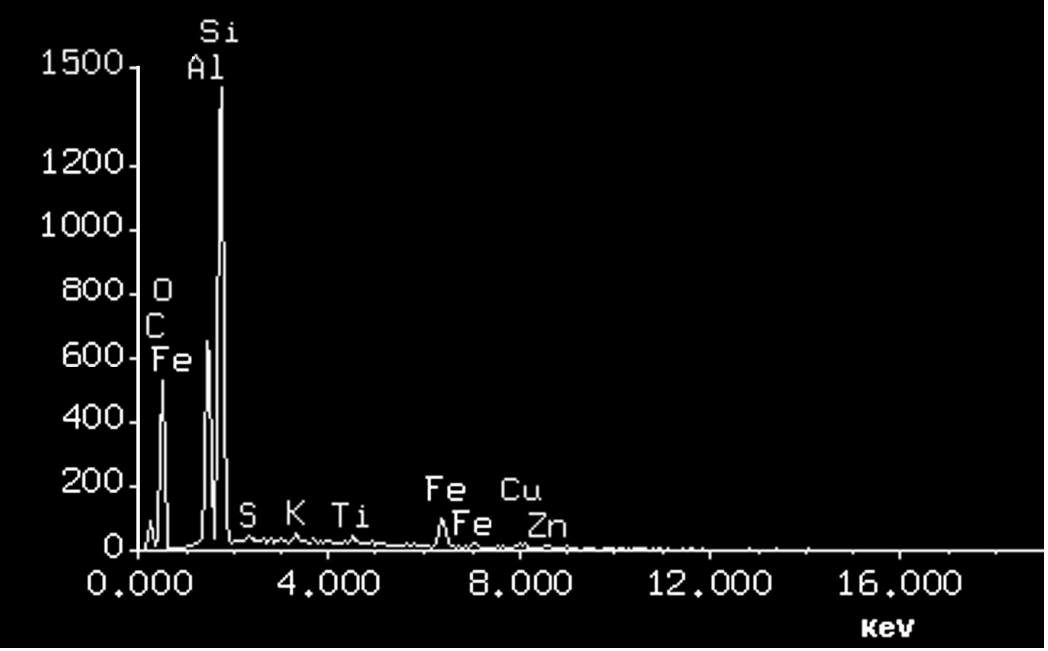

Figura 6d. Espectro EDS da camada central. 


\section{DISCUSSÃO}

A condutividade elétrica (CE) encontrada para as estações PET 1, 2, 3, 4, 5, 6, 7, 8 e 9 exibiu valores mais elevados que das PET 10, 11, 12, 13, 14, 15 e 16, devido ao efeito da diluição decorrente das chuvas que antecederam as coletas dessas últimas estações.

Além da alteração nos valores da CE, observou-se para os mesmos conjuntos de estações de coleta a elevação dos valores de pH, de 6,98 a 7,40 para 8,20 a 9,16, respectivamente. Provavelmente esse aumento ocorreu como conseqüência da aceleração do processo de decomposição da matéria orgânica dos sedimentos promovida pela oxigenação da coluna d’água devido à ação dos ventos e da chuva ocorridos antes e durante o dia dessas coletas. Fica diagnosticado que estas variações climáticas podem alterar outras características físico-químicas do meio, como o potencial de oxi-redução (Eh), e interferir no processo de remobilização de espécies químicas presentes nos sedimentos. $\mathrm{O}$ mesmo poderia ter ocorrido com o oxigênio dissolvido (OD), mas uma falha no equipamento resultou na leitura de valores muito superiores aos possíveis de serem encontrados $(9,01 \mathrm{mg} / \mathrm{L})$ na temperatura observada no ambiente de coleta, $19^{\circ} \mathrm{C}$, de acordo com Drever (1988).

As concentrações dos metais pesados em solução são baixas ou não detectáveis. O ferro e o zinco são exceções e apareceram também em todos os espectros EDS obtidos para as análises pontuais em organismos fitoplanctônicos, além do Si e O, que compõem as frústulas das diatomáceas, indicando uma relação entre a presença desses elementos disponíveis em solução e sua participação nos processos ou metabolismo biológicos. O zinco presente nos EDS (Figuras 6c e 6d) realizados nas séries de estrias internas da frústula que aparecem na Figura 6a, não está presente na camada silicosa externa (Figura 6b). Não se pode afirmar a presença do cobre nos organismos analisados uma vez que não está bem caracterizado nos respectivos espectros EDS.

Não se deve esquecer que os metais presentes nos sedimentos podem ser disponibilizados continuamente para a coluna d'água, portanto, outros metais como o cromo e o níquel presentes nos sedimentos de topo, também podem ser incorporados pela biota lacustre.

Os fatores de correlação, calculados a partir das concentrações dos elementos químicos presentes nos sedimentos de topo, indicam prováveis associações como: do fósforo, cromo, zinco, ferro e cobre com a matéria orgânica e aluminossilicatos; entre os metais cobre e zinco; dos metais zinco, cobre, cromo, ferro e níquel com o percentual de umidade, indicando possível presença desses, dissolvidos na água dos sedimentos.

Os valores de potenciais de oxi-redução (Eh) negativos, que variam entre $-283 \mathrm{mV}$ e $-362 \mathrm{mV}$, indicam que esses sedimentos se encontram em ambiente redutor e que os metais pesados aí presentes podem se encontrar sob a forma de sulfetos e, portanto, pouco disponíveis. Por outro lado, os elevados valores para a correlação entre as concentrações do cobre e do zinco e os teores de umidade dos sedimentos, podem indicar o grau de complexidade do equilíbrio que se estabelece nesse sistema e da sua fragilidade diante das alterações diárias de temperatura, vento e precipitação pluviométrica.

\section{CONCLUSÃO}

O ambiente lacustre do PET apresentou sensibilidade às alterações climáticas ocorridas entre os dias das coletas, tanto para os sedimentos quanto para a água da interface. Cada um desses fatores irá afetar a relação de transferência de massa, a cinética das reações de superfície e os processos de difusão de metais ao longo da cadeia trófica do ambiente lacustre.

O EDS acoplado MEV demonstrou ser uma técnica importante e auxiliar que permite a realização de análises químicas qualitativas pontuais das diferentes partes de estruturas de organismos ou minerais. Pode ser utilizado na prospeção do grau de contaminação ambiental a partir da identificação de espécies indicadoras ambientais de origem biológica ou inorgânica.

\section{REFERÊNCIAS BIBLIOGRÁFICAS}

BAUDO, R.; GIESY, J.; MUNTAU, H. Sediments: chemistry and toxicity of in-place pollutants. Ann Arbor: Lewis Publishers, 1990. 405 p.

BEYRUTH, Z. Fitoplâncton em lagos do Parque Ecológico do Tietê, São Paulo, 1986-1987. Estudo para a reabilitação. Revista DAEE-SABESP, $\mathrm{n}^{\circ}$ 172, p. 11-13, 1993.

BRANCO, S. M. Hidrobiologia aplicada à engenharia sanitária. $3^{\mathrm{a}}$ ed. São Paulo: CETESB/ASCETESB, 1986. $640 \mathrm{p}$.

CANTER-LUND, H.; LUND, J. W.G. Freshwater algae: their microscopic world explored. Bristol, England: Biopress Limited, 1996. 360 p.

DEKER, C. M. Efeitos da inundação do rio Tietê na estrutura da comunidade zooplantônica do lago do Parque Ecológico do Tietê - São Paulo. 2000. 104 p. Tese (Mestrado) - Faculdade de Saúde Pública, Universidade de São Paulo, São Paulo, 2000.

DREVER, J. I. The geochemistry of natural waters. $2^{\mathrm{a}}$ ed. 
New Jersey: Prentice Hall, 1988. 437 p.

FORTI, M. C. Instruções para coletas e preparação das amostras de águas e solo na toposseqüência de Humaitá. São Paulo: Nupegel/USP, PRONEX. 1998. 19p.

HÅKANSSON, H.; OLSSON, S.; JIANG, H.; GARBESCHÖNBERG, C. D. The sediment diatom association and chemistry of surface sediments of lake Belauer See, northern Germany. Diatom Research, v. 13, n. 1, p. 63-91, 1998.

HAKANSON, L.; JANSSON, M. Principles of lake sedimentology. Germany: Springer-Verlag, 1983. 316 p.

MEDLEY, C. N.; CLEMENTS, W. H. Responses of diatom communities to heavy metals in streams: the influence of longitudinal variation. Ecological Applications, v. 8, n. 3, p. 631-644, 1998.

MILANI, G. M. Estudo da contaminação pelos metais Cu, $\mathrm{Pb}$, Cd e Zn na rede trófica dos reservatórios de Taiaçupeba e do Parque Ecológico do Tietê, SP. 2000. 66 p. Tese (Mestrado) - Faculdade de Saúde Pública, Universidade de São Paulo, São Paulo, 2000.

MUDROCH, A.; AZCUE, J. M. Manual of Aquatic Sediment Sampling. Boca Raton: Lewis Publishers, 1995. 219 p.

PROMON 1976. INFR76. 